\title{
Effects Assessment of Summer Fishing Moratorium in Daya Bay in the Northern South China Sea
}

\author{
Jing Yu ${ }^{1 *}$, Qiwei Hu1,2, Huarong Yuan'1*, Fei Tong1, Pimao Chen ${ }^{1}$, Jiangmei Mao, ${ }^{1,2}$ \\ ${ }^{1}$ South China Sea Fisheries Research Institute, Chinese Academy of Fishery Sciences/Key Laboratory of Fishery Ecology and \\ Environment, Guangdong Province/Scientific Observing and Experimental Station of South China Sea Fishery Resources and \\ Environment, Ministry of Agriculture/Key Laboratory of Marine Ranching Technology, CAFS, Guangzhou, China \\ ${ }^{2}$ College of Marine Science, Shanghai Ocean University, Shanghai, China \\ Email: *yujing@scsfri.ac.cn, *yhr_gd@163.com
}

How to cite this paper: $\mathrm{Yu}, \mathrm{J} ., \mathrm{Hu}, \mathrm{Q} . \mathrm{W}$., Yuan, H.R., Tong, F., Chen, P.M. and Mao, J.M. (2017) Effects Assessment of Summer Fishing Moratorium in Daya Bay in the Northern South China Sea. Journal of Geoscience and Environment Protection, 5, 96108.

https://doi.org/10.4236/gep.2017.57010

Received: June 1, 2017

Accepted: July 14, 2017

Published: July 17, 2017

Copyright $\odot 2017$ by authors and Scientific Research Publishing Inc. This work is licensed under the Creative Commons Attribution International License (CC BY 4.0).

http://creativecommons.org/licenses/by/4.0/

\begin{abstract}
In order to assess effects of Summer Fishing Moratorium (SFM) in Daya Bay, variations in stock density, fish diversity, fish species composition, fish body length and weight, and bio-environments during the pre-SFM (May in 2015) and post-SFM (August in 2015) in Daya Bay were analyzed, based on trawl survey data. Results showed that the average stock density in the post-SFM was 5.65 times of that in the pre-SFM, and the average species numbers in the post-SFM was 1.76 times of that in the pre-SFM. Analysis of fish body length and weight indicated that fish grew faster during the SFM, and body weight was more uniform in the post-SFM. In the post-SFM, the Shannon-Wiener diversity index and Pielou evenness index increased by 0.36 and 0.14 , respectively, indicating that the fish biodiversity and community structure improved. SFM alleviated fishing intensity, recovered and conserved coastal fish resource. In order to improve efficiency and impacts of SFM and to promote sustainable development of coastal fish resource, prolonging the time of SFM, reducing the number of coastal fishing boats and enforcing the conservation of fish resources were suggested.
\end{abstract}

\section{Keywords}

Summer Fishing Moratorium, Fishery Resources, Variation, Daya Bay

\section{Introduction}

Located in the northern South China Sea (NSCS), Daya Bay is a typical subtropical drowned-valley bay with numerous islands, zigzag shorelines, superior nat- 
ural environment and rich biological resources. Daya Bay used to be the place for numerous commercial fishes to spawn, forage and fatten and also an important fishery culturing resource base in the NSCS [1] [2] [3] [4] [5]. Over the past thirty years, the quantity of fish species in Daya Bay has declined; species composition has been changing and fishery resources are faced with exhaustion, due to environmental pollution, over-exploitation and climatic change [6] [7] [8] [9]. In order to restore severely receded offshore fishery resources, the Ministry of Agriculture of China started to implement Summer Fishing Moratorium (SFM) in the coasts of SCS since 1999, which has been implemented for 18 years [10]. The effect evaluation of SMF included resource variation, ecological protection, economic benefit and social influence, et al. [11] [12] [13]. Until now, few research on fish species, resource quantity and diversity during the pre- and postSFM in Daya Bay.

Although SFM plays a positive role in mitigating recession of fishery resources and conserving marine resources, there are problems such as insufficient stock assessment during the pre- and post-SFM and unable thorough containment resource recession, etc [11] [12] [13] [14]. Daya Bay provides an ideal area to assess effects of SFM to coastal fisheries in the NSCS, because of its semi-closed shape and suitable size [15]. In this study, based on survey data of fishery resources and relevant fisheries statistics, variations of fish resources in Daya Bay during the pre- and post-SFM and the influence of SFM on coasts of NSCS were analyzed. Suggestions for the maintenance of offshore fishery resources in the NSCS were proposed. Results of this work will help better evaluate affections of SFM and promotion of sustainable utilization and management of offshore fishery resources in the NSCS.

\section{Materials and Methods}

\subsection{Survey Data}

Trawl surveys of Daya Bay was conducted according to the set sites during the pre-(May, 2015) and post-SFM (August, 2015; Figure 1; Table 1). The monitoring ship entered the preset site and GPS was used for localization. All monitoring and sampling methods were implemented according to National Marine Monitoring Standard, China [16] [17]. Power of the trawl survey ship was 219.32 $\mathrm{kW}$, total tonnage was $104.98 \mathrm{t}$, and both head line and foot line of trawl net were $46 \mathrm{~m}$. Trawl survey was implemented once in each planned sampling site, with trawl speed $3.0 \mathrm{n} \mathrm{mile/h}$ and dragging interval $1 \mathrm{~h}$. Caught samples from all sites were analyzed and determined on the spot. When the total weight of caught samples was less than $20 \mathrm{~kg}$, all samples were analyzed and determined. When the total weight was greater than $20 \mathrm{~kg}$, large individuals and rare species were picked out firstly, other small and miscellaneous fish samples were randomly collected. Then analysis and determination for the samples were conducted. Caught nektons from all sites were identified to species. Weight, tail number, range of body length and range of weight were determined and recorded, respectively. 


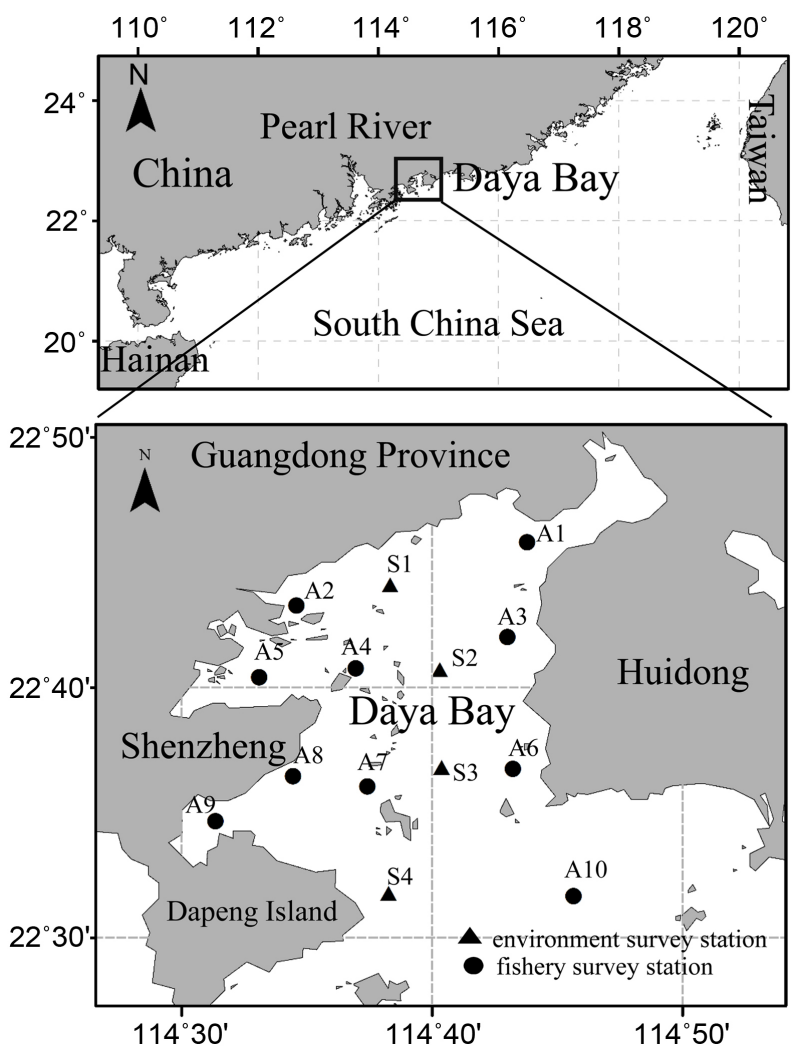

Figure 1. Research area with survey stations.

Table 1. GPS coordinates for the survey stations in Daya bay.

\begin{tabular}{ccc}
\hline Station & Longitude $\left({ }^{\circ} \mathrm{E}\right)$ & Latitude $\left({ }^{\circ} \mathrm{N}\right)$ \\
\hline A1 & 114.7298 & 22.7635 \\
A2 & 114.5764 & 22.7213 \\
A3 & 114.7167 & 22.7003 \\
A4 & 114.6158 & 22.6795 \\
A5 & 114.5516 & 22.6735 \\
A6 & 114.7204 & 22.6125 \\
A7 & 114.6236 & 22.6008 \\
A8 & 114.5740 & 22.6076 \\
A9 & 114.5225 & 22.5776 \\
A10 & 114.7608 & 22.5277 \\
S1 & 114.6387 & 22.7351 \\
S2 & 114.6717 & 22.6787 \\
S3 & 114.6730 & 22.6136 \\
S4 & 114.6376 & 22.5296 \\
\hline
\end{tabular}

\subsection{Data Analysis}

Sweeping area method [18] was used to estimate fishery resource density $(D)$ with unit being $\mathrm{kg} \cdot \mathrm{km}^{-2}$ or tail $\mathrm{km}^{-2}$, and calculation formula is as below: 


$$
D=\frac{C}{q a},
$$

where $C$ is catch per unit effort, $a$ is sampling area of netting gear per hour and $q$ is capture rate of netting gear (taken as 0.5).

Shannon-Wiener diversity index $(H)$ [19], Pielou evenness index $(J)$ [20] and Dominance index $(Y)$ [21] were used to analyze community diversity of fishery resources:

$$
\begin{gathered}
H^{\prime}=-\sum_{i=1}^{S} p_{i} \ln P_{i}, \\
J^{\prime}=\frac{H^{\prime}}{\log _{2} S}, \\
Y=\frac{n_{i}}{N} \times f_{i},
\end{gathered}
$$

where $N$ is the total number of catch species from all stations; $P_{i}$ is the ratio of number of the $i$ th individuals to total number of individuals; $n_{i}$ is the total number of the $i$ th species; $N$ is the total number of catch tail from all stations and $f_{i}$ is the appearance frequency in all survey stations. The species is the dominant species in the community when its $Y>0.02$.

Different value was defined as the difference of factor values between the preand post-SFM. Difference value of body length is the value obtained by deducting minimum value from maximum value of fish body length pre- (post-) SFM. Difference value of weight is the value obtained by deducting minimum value from maximum value of fish weight pre- (post-) SFM and difference value of environmental factors is the difference obtained by deducting environmental factor during the pre-SFM from corresponding environmental factor during the post-SFM.

\section{Results}

\subsection{Variation of Species Composition and Stock Density in the Pre- and Post-SFM}

Species number of fishery resources during the pre- and post-SFM was 30 and 24 , respectively. Total species number in the post-SFM reduced by $20 \%$, species number of fishes, shrimps, crabs and cephalopods were also smaller than those in the pre-SFM (Figure 2).

Average stock density of fishery resources were $1142.29 \mathrm{~kg} \cdot \mathrm{km}^{-2}$ and 1227.32 $\mathrm{kg} \cdot \mathrm{km}^{-2}$, respectively. Average tail stock density were $142,266.9$ tail $\mathrm{km}^{-2}$ and 89171.7 tail $\mathrm{km}^{-2}$, respectively (Figure 3). Average stock density increased greatly in the post-SFM, being 5.65 times of that in the pre-SFM; and average tail stock density increased slightly, being 1.76 times of that in the pre-SFM. Squillid organisms were not captured during the whole survey period (Figure 3).

\subsection{Variations of Fish Body Length and Weight in the Pre- and Post-SFM}

Linear fitting of the relationship between fish body length and weight in the pre- 


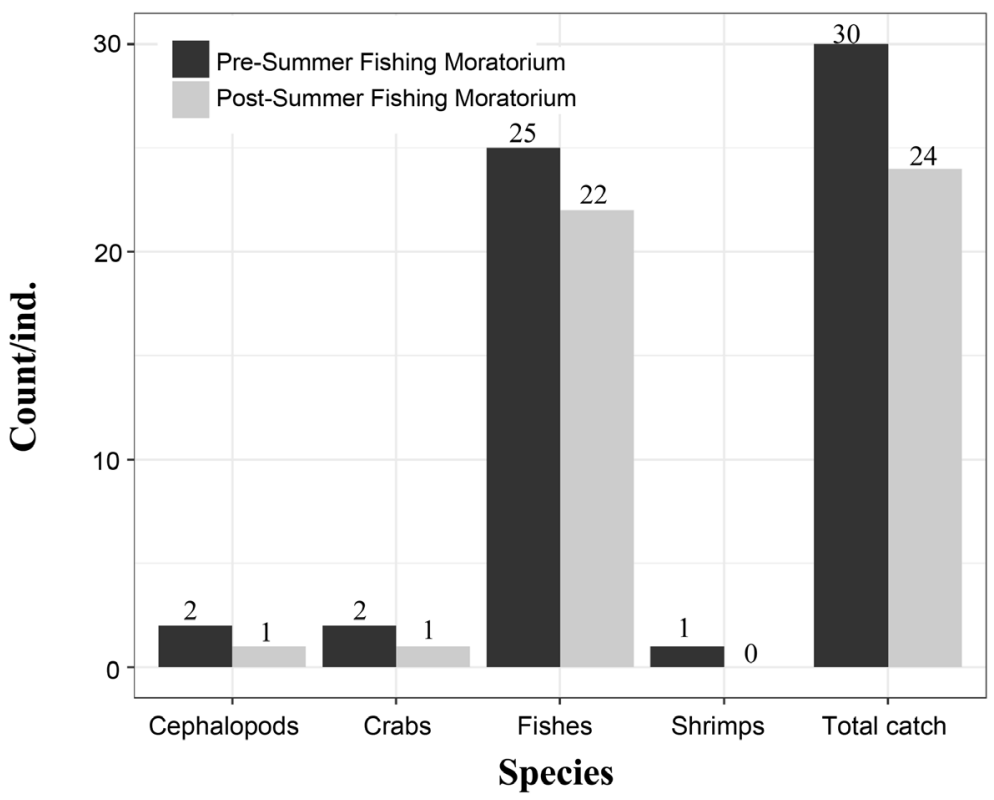

Figure 2. Species number in the pre- and post-SFM in Daya Bay.
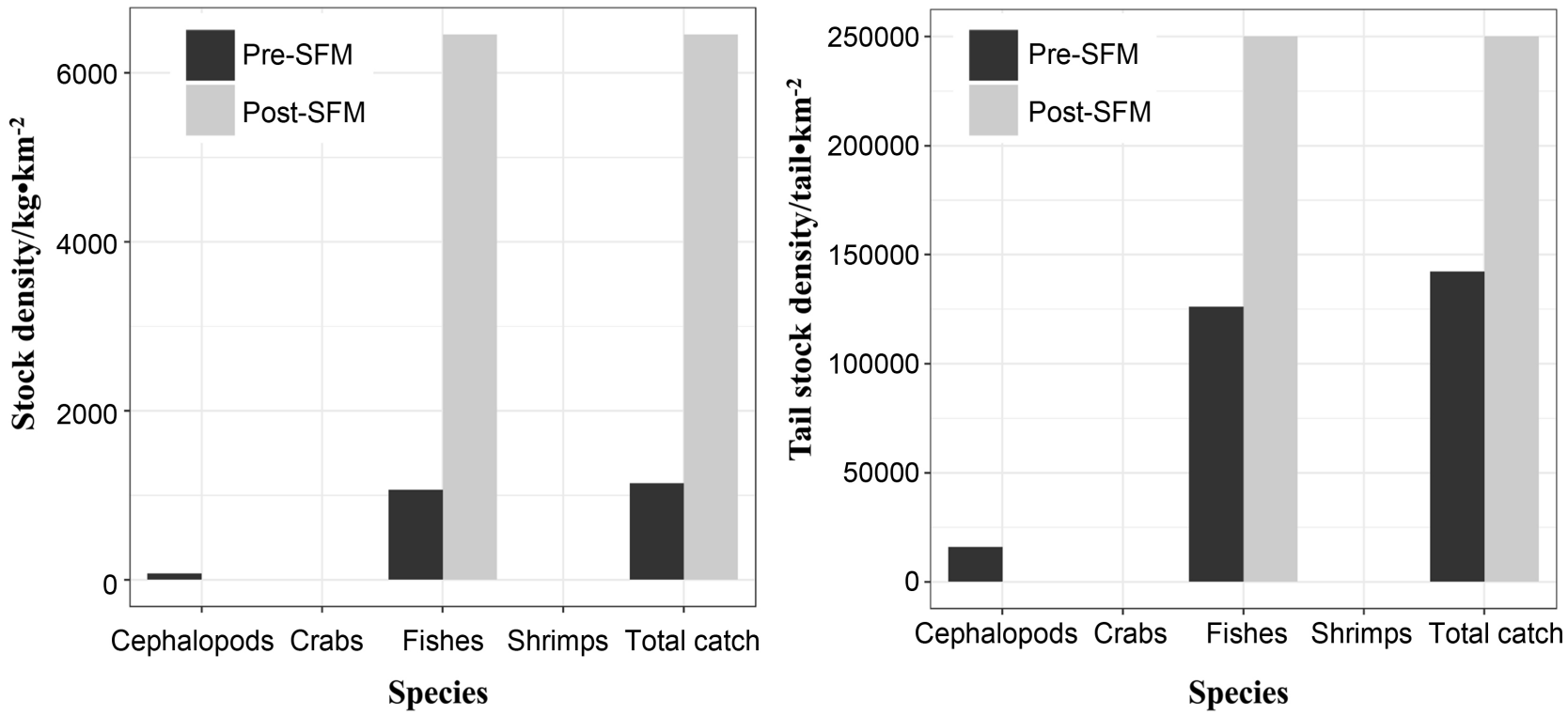

Figure 3. Stock density and tail stock density in the pre- and post- SFM in Daya Bay.

and and post-SFM in Daya Bay indicated that range of fish body length was 0 $175 \mathrm{~mm}$, range of fish weight was $0-150 \mathrm{~g}$, and fitted correlation coefficient between fish body length and weight was 0.50 in the pre-SFM (Figure 4). In the post SFM, range of fish body length was $0-200 \mathrm{~mm}$, range of fish weight was 0 $175 \mathrm{~g}$, and fitted correlation coefficient between fish body length and weight was 0.58 (Figure 4) which increased by 0.08 when compared with that in the preSFM.

Box-plot distribution analysis of variations of fish body length and weight in the pre- and post-SFM in Daya Bay was conducted. Results showed that the main variation range of difference value between maximum body length and 


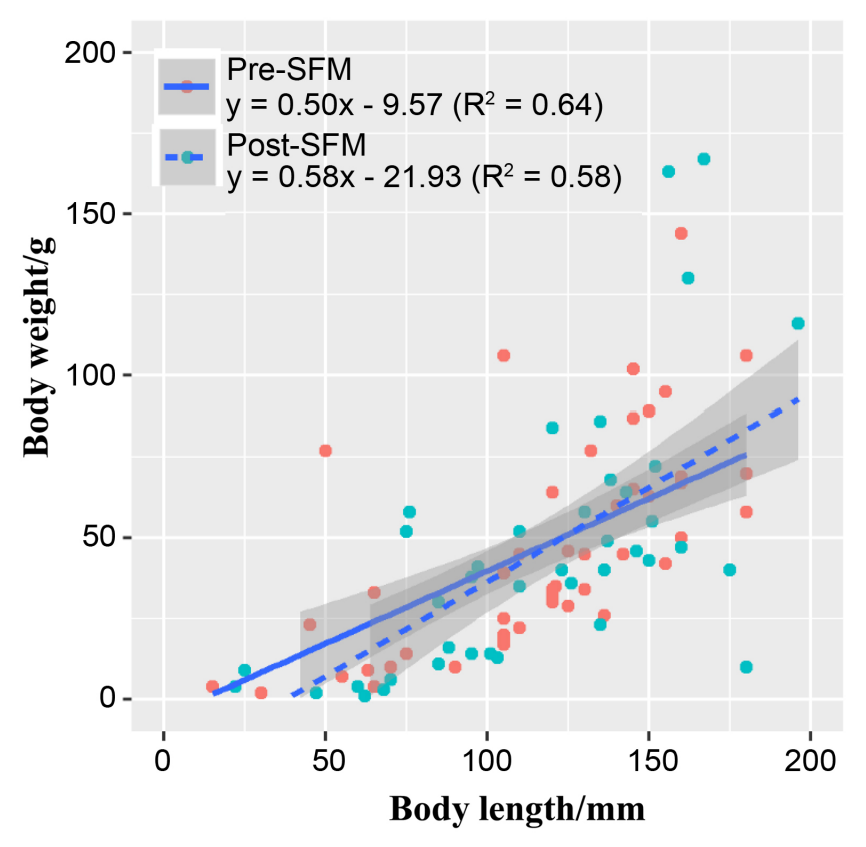

Figure 4. Relationship between fish body length and weight in the pre- and post-SFM in Daya Bay.

minimum body length in the pre-SFM was $3-35 \mathrm{~mm}$ and 50\% quantile was 15 $\mathrm{mm}$ (Figure 5). Major variation of difference value between maximum fish body length and minimum fish body length was $0-39.5 \mathrm{~mm}$, and $50 \%$ quantile was $14.5 \mathrm{~mm}$ (Figure 5). Variation of fish body length in the post-SFM was expanded, and overall fish body length was smaller than that in the pre-SFM. In the pre-SFM, major variation of difference value between maximum fish weight and minimum fish weight was $1-47 \mathrm{~g}$, and 50\% quantile was $21.5 \mathrm{~g}$ (Figure 5). In the post-SFM, major variation of difference value was $0-34.5 \mathrm{~g}$ and $50 \%$ quantile was $4.5 \mathrm{~g}$. Variation amplitude of fish weight in the post-SFM decreased (Figure 5).

\subsection{Variations of Fish Diversity and Dominant Species in the Pre- and Post-SFM}

Fish biodiversity in the pre- and post-SFM in Daya Bay were showed in Figure 6. In the pre-SFM, Shannon-Wiener diversity index $(H)$ and Pielou evenness index $(J)$ were 2.32 and 0.46 , respectively. In the post-SFM, $H^{\prime}$ and $J^{\prime}$ were 2.68 and 0.59 , respectively.

Catch species in the pre- and post-SFM in Daya Bay were analyzed (Figure 7). Major catch species were 13 species in the pre-SFM, being Sardinella nymphaea, Trichiurus haumela, Decapterus maruadsi, Clupanodon punctatus, Loligo duvaucelii, Psenopsis anomala, Gastrophysus lunaris, Pampus argenteus, Caranx kalla, Sardinella aurita, Leiognathus ruconius, Setipinna taty and Thrissa kammalensis. Stock density of Sardinella nymphaea was the highest, being 272.75 $\mathrm{kg} \cdot \mathrm{km}^{-2}$ (Figure 7). 8 dominant species were caught in the post-SFM, being $\mathrm{Si}_{\text {- }}$ ganus oramin, Thrissa vitirostris, Gastrophysus lunaris, Sardinella nymphaea, 


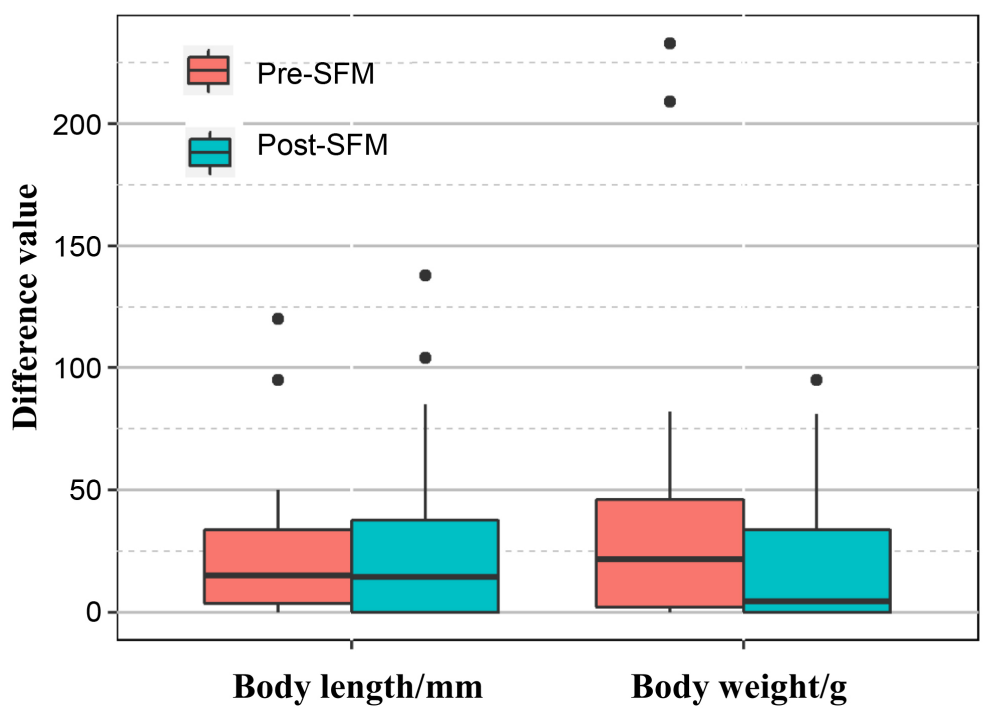

Figure 5. Box-plot distribution of fish body length and weight in the preand post-SFM in Daya Bay (Whisker of box-plot indicates the rang of plus or minus 1.5 times IQR).

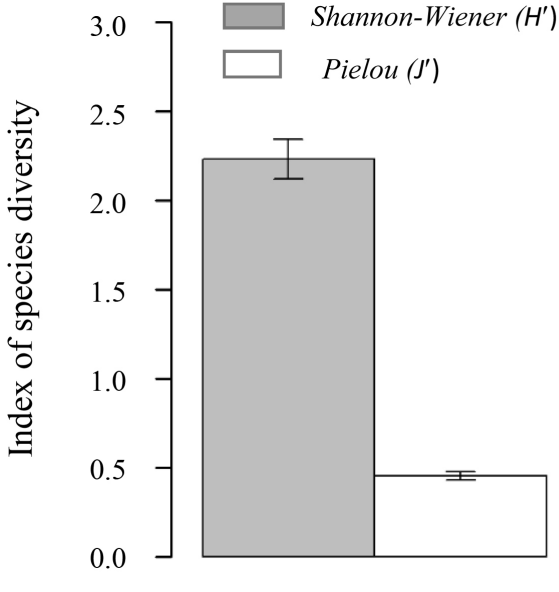

Pre-SFM

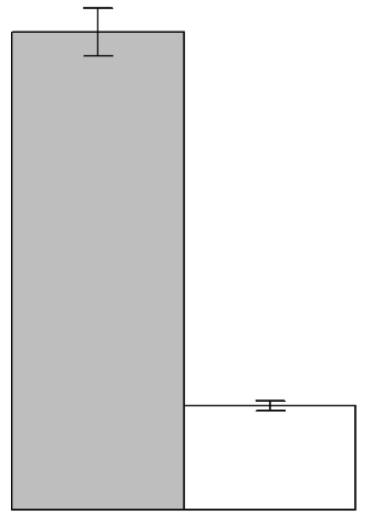

Post-SFM

Figure 6. Biodiversity index in the pre- and post-SFM in Daya Bay.

Sardine llajussieu, Decapterus maruadsi, Stolephorus indicus and Trichiu rushaumela. Stock density of Thrissa vitirostris was the highest, being 391.09 $\mathrm{kg} \cdot \mathrm{km}^{-2}$ (Figure 7). The major catch species in the pre- and post-SFM in Daya Bay were pelagic fishes, and stock density in the post-SFM increased obviously (Figure 7).

\section{Discussion}

\subsection{Stock Density Increase in the Post-SFM in Daya Bay}

SFM is a significant measure protecting living aquatic resources and promoting sustainable utilization of fishery resources and this measure plays a positive role in mitigating the contradiction between insufficient catchability of fishery resources and excessive catching intensity [22]. This research indicated that average 


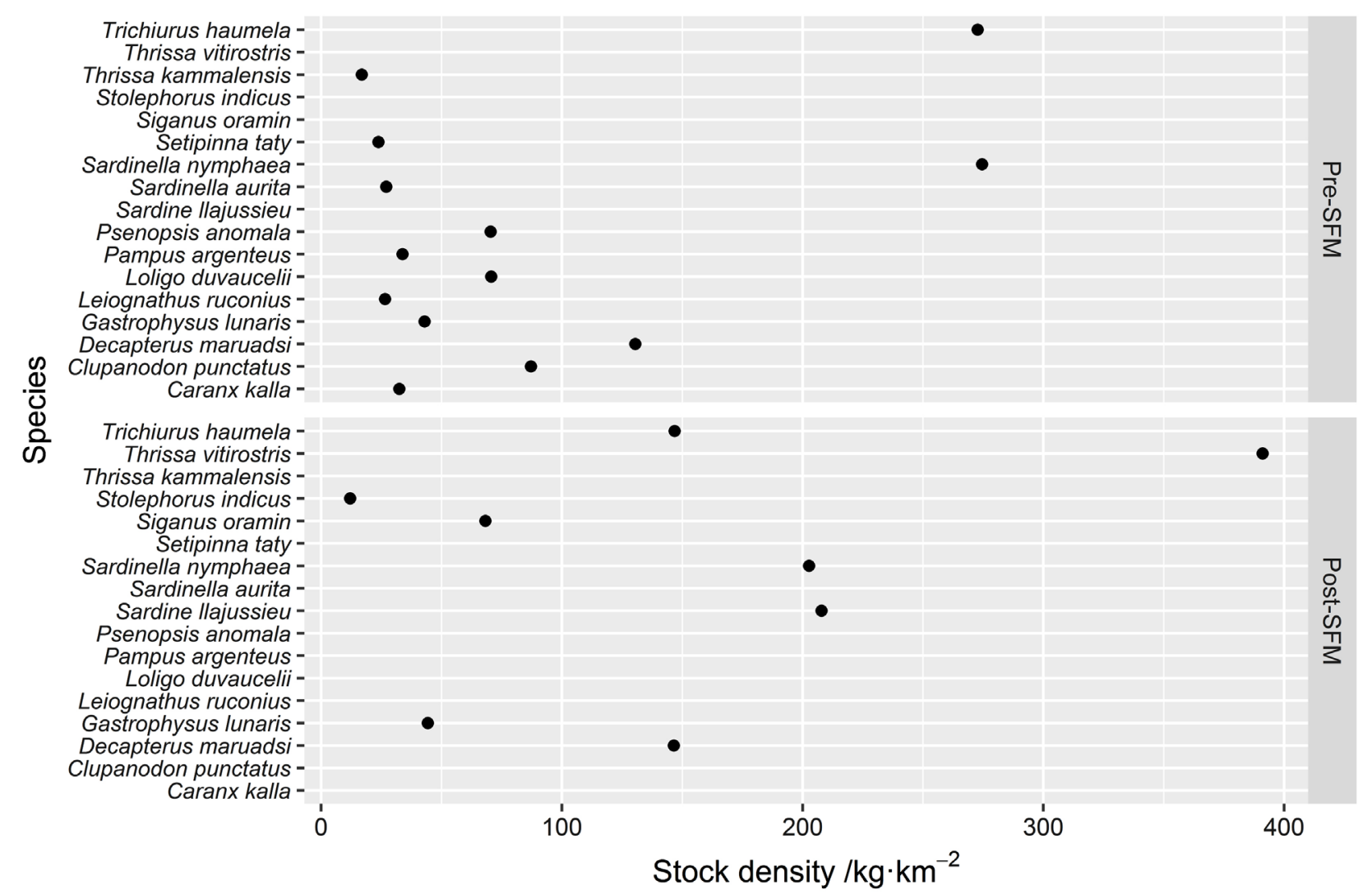

Figure 7. Stock density of major species in the pre- and post-SFM in Daya Bay.

stock density was 5.65 times of that in the pre-SFM, average tail stock density was 1.76 times of that in the pre-SFM, and fitted correlation coefficient of fish body length and weight in the post-SFM increased (Figure 2 and Figure 3), also. Variation range of stock density doubled. Moreover, stock density of major species in the post-SFM was greater than those in the pre-SFM, indicating that fishery resources in the post-SFM increased in quantity (Figure 3). In addition, fish body weights in the post-SFM were more even, which indicated that juvenile fishes during SFM obtained favorable growth. SFM period was a spawning peak season of commercial fishes in Daya Bay [4]. Moratorium system completely restricted fishing gears and catching methods which generated serious harm to juvenile fishes and lowered catching intensity so as to provide a stable environment for growth of spawns and juvenile fishes. Furthermore, compared with the situation in the pre-SFM, in the post-SFM, water temperature increased and chlorophyll a concentration in water body increased in Daya Bay (Figure 8), providing appropriate environment and relatively abundant baits for the growth of juvenile fishes so that their body lengths and weights continuously increased and the catch rate in the post-SFM increased obviously (Figure 4). Previous research on SFM in Daya Bay during 2007-2008 indicated that stock density increased in the post-SFM [23], which was consistent with this result. Compared with the situation in 2007, in 2008, fishery resources in the post-SFM reduced [23] [24]. This research also indicated that the quantity of fish resources in the 


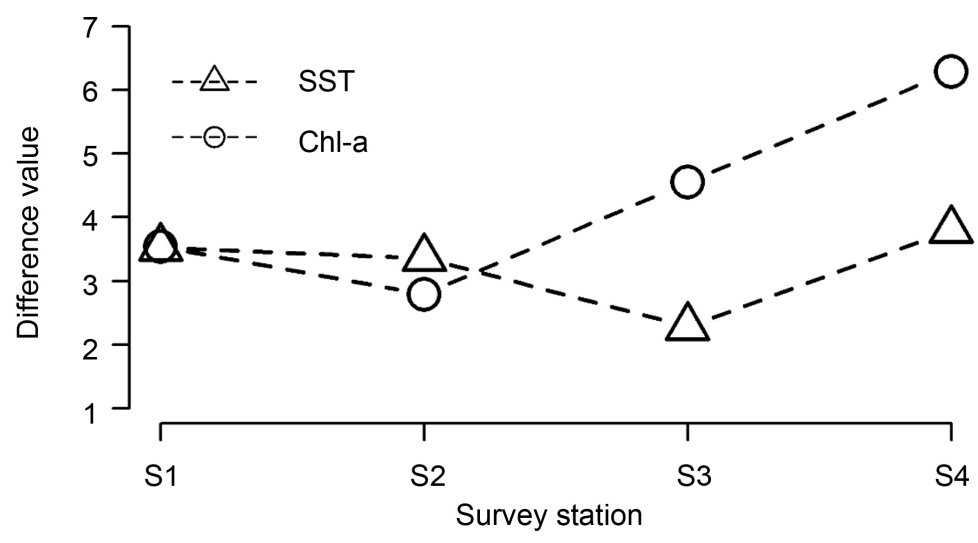

Figure 8. Difference values of water temperature and chlorophyll a concentration in the pre- and post-SFM in Daya Bay.

post-SFM in 2015 was smaller than those in 2007 and 2008, mainly because short-term effect of SFM was significant but it's difficult to consolidate the effect for a long term.

\subsection{Fish Diversity Rise in the Post-SFM in Daya Bay}

This study indicated that biodiversity indexes in the post-SFM were higher than those in the pre-SFM, diversity index $H^{\prime}$ and Pielou evenness index $J$ increased by 0.36 and 0.14 , respectively (Figure 6 ). The intensity of human activities on fish community during SFM reduced to the lowest extent, the fishery community structure was improved [11] [24]. Fishery survey in Daya Bay during 20042005 showed that the species number of meso-demersal fishes was the greatest, followed by pelagic and demersal fishes [25]. The diversity index in summer was 3.82 and the evenness index was 0.65 [25]. Although fishery resources in Daya Bay recovered slightly and stock size increased in the post-SFM, both diversity index $(H)$ and evenness index $(J)$ in the post-SFM were lower than those in the same periods during 2004-2005. Moreover, it's found that the species number in the post-SFM was smaller than that in the pre-SFM, with 6 fish species were reduced (Figure 2). This was possibly connected with the limited influence by SFM on recovering biological population structure of commercial fishes in Daya Bay [22]. SFM provided a certain period for maintenance of fishery resources, but it also shortened catching season. In the post-SFM, fishing intensity was aggravated, and then effects of SFM on resource conservation disappeared rapidly in the same year under this high fishing intensity [22] [26]. On the other hand, over the recent thirty years the fishing intensity in Daya Bay increased continuously. Besides, rapid development of industry, agriculture especially construction and operation of large-scale projects such as Daya Bay Nuclear Power Plant and Petrochemicals brought about enormous pressure to fishery ecological environment. Therefore, fishery resources in Daya Bay recessed seriously [27] [28].

\subsection{Suggestions for Continuous Perfection of SFM System}

SFM system has been one of the most substantial protective measures for fishery 
resources so far [26]. Up to 2017, SFM in the South China Sea had been continuously implemented for 19 years, which basically maintained stability of fishery resources and stock size, objectively slowed down continuously degraded biological resources and generated significant ecological, economic and social benefits. However, fishing production in Daya Bay itself has certain limitations, such as excessive fishing intensity during non-SFM period, recession of coastal fishery resources and ineffective supervision for fishing power, all of which affect effects of SFM system [22]. It's suggested that SFM system should be further perfected from three aspects as the following.

Prolong SFM period appropriately and execute SFM strictly. Influenced by global change and increasing human activities, coastal fish spawning period goes ahead of schedule [11]. Prolongation of SFM contributes to better protection of spawning populations and juvenile fishes and promotion of sustainable development of coastal fishery resources. From the aspect of resource conservation, the longer the SFM lasts, the better the maintenance effect on fishery resources. At present, because of ineffective supervision, illegal fishing during SFM is not eliminated though forbidden, which generates enormous damage to the growth of juvenile fishes. Therefore, SFM system should be executed strictly through intensify forbidding on illegal fishing behaviors [26], to ensure recovery and maintenance effects of SFM.

Reduce and control coastal fishing boats and develop deep-sea fishery. Because of rapid development of ship-making and catching technologies in recent years, coastal fishing intensity has been seriously excessive [22]. On account of rapid development of aquatic product market and continuously rising market price, in the post-SFM, more fishermen have been occupied in fishing activities so that competition is aggravated and effect of SFM is exhausted within a short period. In fishery resources management, application and disassembly of shipreduction projects should be standardized, fishery licensing system should be intensified, stipulations about fishermen qualification for fishing should be supplemented and invested capital, revise and formulate feasible fishing boat scrapping system should be examined, etc. [10]. In Daya Bay, controlling fishing boats, guiding fishermen to develop new fishing grounds towards deep sea were suggested. Deep sea area beyond continental shelf of the South China Sea reserves abundant oceanic cephalopods and tunas, especially Sthenoteuthis oualaniensis and Thunnus albacares have development potential [29]. Therefore, we should guide fishing boats to transfer towards southern deepwater region of the South China Sea and mobilize development of relevant industries including processing and trade, which can not only relieve pressure of production and profession transfer on fishermen, lower nearshore fishing intensity and promote adjustment of fishing structure but also has potential economic, social and ecological benefits.

Enhance resource conservation and boost ecological restoration. Deployment of artificial reefs has positive effects for stock enhancement significant conservation effect on marine organisms [30] [31] [32]. In recent years, researches on ar- 
tificial reefs in Daya Bay, China indicated that species number and quantity of planktons in reef areas increased, and stock density in the reef area were higher than those at control stations in the same period, showing that effects of artificial reefs on resource conservation was prominent [32]. SFM lasts a short period, effects of artificial reefs on fishery restoration and maintenance and remediation of marine ecological environment can exist for a long time [33], and therefore, artificial reefs constitute a favorable supplementation for SFM. In addition, releasing also constitutes one of effective measures of restoring receded fishery resources, optimizing production structure and improving marine ecological environment [34] [35]. Since the 1990s, releasing during SFM period has been continuously implemented in Daya Bay, and this obtained favorable effects on improving structure of fishery resources, supplementing quantity of commercial fishes, etc. [36] [37]. Moreover, May-August is spawning period of most fishes in Daya Bay, it is appropriate to implement proliferation and releasing of fishes [35]. Hence, it's suggested that stock enhancement and releasing should be carried out in appropriate period.

\section{Conclusion}

A preliminary analysis of variations in stock density, fish body length and weight and species composition in the pre- and post-SFM in Daya Bay was conducted, through trawl survey data. Results showed that the stock density, species number, biodiversity and evenness index increased in the post-SFM indicating that structure of ecological community improved. Therefore, SFM lowered offshore catching intensity and had the effect of restoring and conserving fishery resources. Prolonging SFM period, reducing and controlling coastal fishing and intensifying resource conservation were suggested to be taken in order to better perfect SFM system and boost sustainable development of coastal fishing.

\section{Acknowledgements}

This work was supported by National Key Technology Support Program (No. 2012BAD18B01, 2012BAD18B02), the Science and Technology Project of Shenzhen of China (No. JSGG20141015154342147, JCYJ20160331141759795), and the National Special Fund for Agroscientific Research in the Public Interest of China (No. 201003068).

\section{References}

[1] The Third Research Institution of State Oceanic Administration. (1990) Collections of Papers on Marine Ecoloy in the Dayya Bay Part 3. Ocean Press, Beijing.

[2] Chen, P.M., Yuan, H.R., Jia, X.P., Qin, C.X., Cai, W.G. and Yu, J. (2013) Changes in Fishery Resources of Yangmeikeng Artificial Reef Area in Daya Bay. South China Fisheries Science, 9, 100-108.

[3] Li, N.N., Dong, L.N., Li, Y.Z., Ai, H., Li, X., Chen, G.B. and Shi, B.R. (2011) Taxonomic Diversity of Fish Species in the Daya Bay, the South China Sea. Journal of Fisheries of China, 35, 863-870. https://doi.org/10.3724/SP.J.1231.2011.17363

[4] Lin, Z.J., Wang, X.H. and Jiang, Y.E. (2010) Distribution and Species Composition 
of Fish Eggs in Daya Bay. Journal of Fisheries of China, 17, 543-550.

[5] Yu, J., Tang, D.L., Wang, S., Lian, J. and Wang, Y. (2007) Changes of Water Temperature and Harmful Algal Bloom in the Daya Bay in the Northern South China Sea. Bulletin of Marine Science, 9, 25-33.

[6] Sun, D.R. and Lin, Z.J. (2004) Variations of Major Commercial Fish Stocks and Strategies for Fishery Management in Beibu Gulf. Journal of Tropical Oceanography, 23, 62-68.

[7] Wang, Y.S., Wang, Z.D. and Huang, L.M. (2004) Environment Changes and Trends in Daya Bay in Recent 20 Years. Journal of Tropical Oceanography, 23, 85-95.

[8] Wang, Y.S., Lou, Z.P., Sun, C.C. and Sun, S. (2008) Ecological Environment Changes in Daya Bay, China, from 1982 to 2004. Marine Pollution Bulletin, 56, 1871-1879. https://doi.org/10.1016/j.marpolbul.2008.07.017

[9] Yu, J., Chen, P.M. and Zhao, M. (2014) Satellite Remote Sensing Assessment of Ecological Effects of Artificial Reefs in Daya Bay, China. Remote Sensing and Smart City, 64, 269-275. https://doi.org/10.2495/RSSC140321

[10] Chen, J.H. (2008) A Review of the Practice of Summer Fishing Moratorium: The Conservation of Resources in the Season. China Fishery, 6, 17-24.

[11] Shi, Y.R., Li, Y.Z. and Sun, D.F. (2008) Analysis on the Decades of the South China Sea from the Perspective of Resource Change, Ecological Protection, Economic Benefit and Social Impact. China Fishery, 349, 14-16.

[12] Nguyen, D.T. (2012) China's Fishing Ban in the South China Sea: Implications for Territorial Disputes. Nanyang Technological University, 11, 1-10.

[13] Jiang, Y.Z., Cheng, J.H. and Li, S.F. (2009) Temporal Changes in the Fish Community Resulting from a Summer Fishing Moratorium in the Northern East China Sea. Marine Ecology Progress, 387, 265-273. https://doi.org/10.3354/meps08078

[14] Chen, P.M., Qin, C.X. and Yu, J. (2015) Evaluation of the Effect of Stock Enhancement in the Coastal Waters of Guangdong, China. Fisheries Management \& Ecology, 22, 172-180. https://doi.org/10.1111/fme.12113

[15] Yin, J.P., Wang, Y.S., Xu, J.R., Sun, C.C. and Zhang, F.Q. (2006) Seasonal Thermocline in the Daya Bay and Its Influence on the Environmental Factors of Seawater. Journal of Tropical Oceanography, 23, 85-95.

[16] The State Bureau of Quality and Technical Supervision (2007) GB 2763-2007 Specification for Oceanographic Survey. China Standard Press, Beijing.

[17] The State Bureau of Quality and Technical Supervision (2007) GB 17378.2-2007 Marine Monitoring Regulations. China Standard Press, Beijing.

[18] Shndo, S. (1973) General Review of the Trawl Fishery and the Demersal Fish Stocks of the South China Sea. Food and Agriculture Organization Fisheries Technical, 16, $1-49$.

[19] Shannon, C.E. and Weaver, W. (1949) The Mathematical Theory of Communication. University of Illinois Press, 19, 1-50.

[20] Pielou E.C. (1966) The Use of Information Theory in the Study of Ecological Succession. Journal of Theoretical Biology, 10, 370-383. https://doi.org/10.1016/0022-5193(66)90133-0

[21] Ding, Y.Q. (1980) Principles of Mathematical Ecology of Insect Populations. Science Press, Beijing.

[22] Zhu, Y.G. (2009) Research on the Effects of China's Summer Fishing MoratoriumA Perspective of Institutional Analysis. China Ocean University, 89, 20-100.

[23] Hou, X.Q., Chen, C.L., Sun, S.L. and Lu, S.Y. (2009) Investigation and Study on Fish 
Resources in Shenzhen Sea Area in 2007-2008. Ocean Development and Management, 26, 106-112.

[24] Chen, C.L., Qu, N.D., Hou, X.Y., Zhang, J.B. and Yang, G.H. (2007) A Survey of Fishery Resources in Shenzhen Sea Area during Closed Fishing Season in Summer. Fisheries Science, 27, 648-651.

[25] Wang, X.H., Du, F.X., Qiu, Y.S., Li, C.H. and Sun, D.R. (2010) Variations of Fish Species Diversity, Faunal Assemblage, and Abundances in Daya Bay in 1980. Chinese Journal of Applied Ecology, 21, 2403-2410.

[26] Chen, J.H. (2008) A Review of the Practice of Summer Fishing Moratorium: The Conservation of Resources in the Season Part 3. China Fishery, 8, 17-19.

[27] Yu, J., Tang, D.L., Imsang, O. and Yao, L.J. (2007) Response of Harmful Algal Blooms to Environmental Changes in Daya Bay, China. Terrestrial Atmospheric \& Oceanic Sciences, 18, 1011-1027. https://doi.org/10.3319/TAO.2007.18.5.1011(Oc)

[28] Yu, J., Tang, D.L., Yao, L.J., Chen, P.M. and Jia, X.P. (2010) Long-Term Water Temperature Variations in Daya Bay, China Using Satellite and in Situ Observations. Terrestrial Atmospheric \& Oceanic Sciences, 21, 393-399. https://doi.org/10.3319/TAO.2009.05.26.01(Oc)

[29] Li, B., Cheng, G.B. and Guo, Y. (2016) Hydroacoustic Assessment of Spatial-Temporal Distribution and Biomass of Fishery Resources in the Central South China Sea. South China Fisheries Science, 12, 28-37.

[30] Rooker, J.R., Dokken, Q.R. and Pattengill, C.V. (1997) Fish Assemblages on Artificial and Natural Reefs in the Flower Garden Banks National Marine Sanctuary, USA. Coral Reefs, 16, 83-92. https://doi.org/10.1007/s003380050062

[31] Yu, J., Chen, P.M., Tang, D.L. and Qin, C.X. (2015) Ecological Effects of Artificial Reefs in Daya Bay of China Observed from Satellite and in Situ Measurements. Advances in Space Research, 55, 2315-2324. https://doi.org/10.1016/j.asr.2015.02.001

[32] Chen, Y.H. (2009) Analysis of Ecological Effects of Southern Dalajia Island Artificial Reef Area in Daya Bay, Guangdong, China. Jinan University, 90, 12-85.

[33] Liu, T.Y. (2003) Construction Status of Artificial Reefs at Home and Abroad. Fishery Modernization, 2003, 36-37.

[34] Molony, B.W., Lenanton, R. and Jackson, G. (2003) Stock Enhancement as a Fisheries Management Tool. Reviews in Fish Biology and Fisheries, 13, 409-432. https://doi.org/10.1007/s11160-004-1886-Z

[35] Liao, X.L., Chen, P.M., Ma, S.W. and Chen, H.G. (2013) Community Structure of Phytoplankton and Its Relationship with Environmental Factors before and after Construction of Artificial Reefs in Yangmeikeng, Daya Bay. South China Fisheries Science, 9, 109-119.

[36] Masuda, R. and Tsukamoto, K. (1998) Stock Enhancement in Japan: Review and Perspective. Bulletin of Marine Science, 62, 337-358.

[37] Lin, J.B., Chen, L., Guo, J.F. and Chen, T. (2001) A Study on Techniques of Pagrosomus Major Enhancement in Daya Bay. Journal of Tropical Oceanography, 25, 7579. 
Submit or recommend next manuscript to SCIRP and we will provide best service for you:

Accepting pre-submission inquiries through Email, Facebook, LinkedIn, Twitter, etc. A wide selection of journals (inclusive of 9 subjects, more than 200 journals)

Providing 24-hour high-quality service

User-friendly online submission system

Fair and swift peer-review system

Efficient typesetting and proofreading procedure

Display of the result of downloads and visits, as well as the number of cited articles Maximum dissemination of your research work

Submit your manuscript at: http://papersubmission.scirp.org/

Or contact gep@scirp.org 